\title{
Industrial Economic Efficiency and Supply-side Reform of Economic Growth in Fujian Province
}

\author{
Hong LEI ${ }^{1, a}$, Lin-Yu FAN ${ }^{2, b}$ and Xue-Yan HUANG ${ }^{3, c}$ \\ ${ }^{1,3}$ School of business administration, Jimei university, Xiamen, Fujian, 361021,P.R.C. \\ ${ }^{2}$ Xiamen university Tan Kah Kee college, Zhangzhou, Fujian, 363105,P.R.C. \\ aleihong@jmu.edu.cn, 'linyufan@xujc.com, chuang xueyan@jmu.stu.cn
}

Keywords: Industrial, Economic Efficiency, Economic Growth, Supply Side Reform.

\begin{abstract}
In This paper the DEA method is used to analyze the economic efficiency of various industries in Fujian Province. Based on the performance of various industries, the problems and influencing factors of industrial development are explored, and puts forward corresponding supply-side reform suggestions.
\end{abstract}

\section{Introduction}

Over the past few decades, low costs of labor, high savings rates, and high investment rates have supported the sustained and rapid growth of economy in China. "High input-high consumption-low efficiency" is the feature of "old normal". Since 2012, the Chinese economy has bid farewell to the rapid growth over the past 30 years and has begun to show a continuous decline. In the fundamental transition of the economic growth phase, the Chinese economy has emerged as a new normal, manifested in the fact that the growth rate has changed from high-speed growth to medium-high-speed growth; the economic structure has been continuously optimized and upgraded, changing from extensive development to connotative growth; and the driving force of growth has been driven by factors. The investment drive has turned to service industry development and innovation driven ${ }^{[1]}$. Supply-side structural reform, and made great efforts to improve the quality and efficiency of the supply system and become a new driving force for economic growth. "Supply-side reforms" means to supply innovations at the element level, supply transformation at the industry level, and supply innovation at the institutional level. Innovation power, structural adjustment power, and institutional innovation power are three major new engines for economic development. Bilateral regulation system at supply and demand promotes economic growth.

Economic development has entered a new mode, focusing on improving the structure and the quality of development. Under the "New Mode" of the economic growth, industrial innovation will be one of the cores of China's supply-side reforms. Industrial innovation has become the best way to improve the quality of economic growth. Industrial innovation strategies have produced industrial production methods, organizational models, and even business models. This paper analyzes the economic development efficiency of sub-industries in Fujian, analyzes the problems in the economic efficiency of each industry, and discusses the deployment of Fujian industrial innovation strategy through supply-side reforms and the impact of industrial innovation on various aspects of the industrial value chain.

\section{Analysis of economic situation under new mode in Fujian}

Located on the southeast coast of Taiwan Strait, Fujian is the starting point of the Maritime Silk Road and has unique geographical advantages.

Since the reform and opening up, especially since the accession to the WTO, Fujian's GDP has jumped from 407.285 billion Yuan in 2001 to 329.928 billion Yuan in 2017, and the volume ranking 10th in the country ${ }^{[2]}$. 
Table 1 Economic growth status of various cities in Fujian in 2015-2017

\begin{tabular}{|l|l|l|l|l|l|l|l|l|}
\hline & & 2014 & \multicolumn{2}{|c|}{2015} & \multicolumn{2}{c|}{2016} & \multicolumn{2}{c|}{2017} \\
\hline Rank & City & Total & Total & $\begin{array}{l}\text { Per-capita } \\
\text { Yuan) }\end{array}$ & Total & $\begin{array}{l}\text { Growth } \\
\text { rate }\end{array}$ & Total & $\begin{array}{l}\text { Growth } \\
\text { rate }\end{array}$ \\
\hline 1 & Quanzhou & 5733.36 & 6137.74 & 72722.04 & 6646.63 & 8.29 & 7548.01 & 8.40 \\
\hline 2 & Fuzhou & 5169.16 & 5618.1 & 75613.73 & 6197.77 & 10.32 & 7104.02 & 8.70 \\
\hline 3 & Xiamen & 3273.54 & 3466.01 & 90971.39 & 3784.25 & 9.18 & 4351.18 & 7.60 \\
\hline 4 & $\begin{array}{l}\text { Zhangzho } \\
\text { u }\end{array}$ & 2506.36 & 2767.45 & 55795.36 & 3125.34 & 12.94 & 3563.48 & 9.10 \\
\hline 5 & Longyan & 1621.21 & 1738.45 & 67121.62 & 1895.67 & 9.04 & 2167.49 & 8.20 \\
\hline 6 & Sanming & 1621.21 & 1713.05 & 68249.00 & 1860.82 & 8.63 & 2136.06 & 7.90 \\
\hline 7 & Putian & 1502.07 & 1655.16 & 58075.79 & 1823.43 & 10.14 & 2045.19 & 8.40 \\
\hline 8 & Ningde & 1377.65 & 1487.65 & 52198.25 & 1623.22 & 8.83 & 1793.87 & 5.30 \\
\hline 9 & Nanping & 1232.56 & 1339.51 & 51126.34 & 1457.74 & 9.61 & 1626.1 & 7.60 \\
\hline & total & 24055.76 & 25979.82 & 68260.17 & 28519.15 & 9.77 & 32298.28 & 8.1 \\
\hline
\end{tabular}

http://www.orz520.com/a/travel/2018/0315/11039474.html?from=haosou

Judging from the GDP and the growth rate, the imbalanced in the regional development in Fujian still exists, and the economic efficiency of development is also uneven. Analyzing the economic development situation in various regions of Fujian and promoting the balanced development is a question worthy of constant exploration.

The reasons for the steady economic growth in Fujian are mainly due to the following factors.

(1) continuously promoting the institutional innovation at the micro-level. With the in-depth implementation of policies and measures, the policy effect is constantly emerging, forming a policy support for stable economic growth. First, it made the policies of deepening the structural reform of agricultural in supply-side and accelerating the new power of agricultural and rural development, and promoted the development of modern agriculture, brand agriculture, intelligent agriculture and ecological agriculture. Second, it is the policy of stabilizing the structure of industrial growth and reducing the cost of the real economy. It has the function of promoting and guiding the relationship between the stable economic growth, the optimization of the industrial structure and the proper handling of the relationship between the industrial development and the resource constraints. Third, promoting the standardization and normalization of administrative examination and approval, reducing the institutional cost of transaction further, lightening the burden of enterprises, and stimulating the vitality of the market.

(2) the emerging momentum of economic growth is rapidly increasing. Digital economy is a new economic form after agricultural economy and industrial economy. It is the sum of a series of economic activities taking digital technology as an important content. In 2016, the average value of the 31 provincial regions was 34.53, and Fujian ranked seventh, there are a lot of characteristics in the aspect of industrial innovation and development ${ }^{[3]}$.

(3) the structural adjustment at both sides of supply and demand continues to develop. In recent years, the demand structure of Fujian has been constantly optimized, and the structural reform of the supply-side has been continuously effective. New consumption formats are developing well, industrial exports continue to grow, investment structure is optimized, and supply-side excess capacity is speeded up.

\section{Evaluation of industrial innovation efficiency in Fujian under the new mode}

The efficiency issue is always the core issue in the study of economics. It is of great significance to reveal the efficiency of industrial development for studying industrial economic issues and formulating relevant policies. The so-called industrial development efficiency refers to the contrast between input and output in the development of industrial economy. For a long time, 
there has been a significant imbalance in the development of China's industrial economy. Many scholars have discussed this issue. However, the focus of attention is on the differences in the development of industrial economy, and less on the factors that influence the efficiency of industrial economic development. This paper uses Data Envelopment Analysis (DEA) to analyze the technical efficiency, pure technical efficiency, scale efficiency, and total factor productivity of Fujian's economic development from 2014 to 2016, so as to provide useful references for the sustainable and healthy development for Fujian's economy in the future.

\section{Model Selection}

In the method of analyzing economic efficiency, DEA model is used to study input-output efficiency when it is mainly divided into non-parametric methods and parameter methods. If the form of the efficiency frontier function chosen does not meet the actual situation, it will affect the calculation of the efficiency value and the conclusions. There are many leading frontier efficiency analysis techniques. This paper selects the improved DEA method that is WHDEA ${ }^{[4]}$ to evaluate the economic development efficiency of Fujian. The WHDEA is actually a partial order with small input, low negative output, and large positive output. The evaluated industry will be compared with other industries to find out the possibility of improvement of each indicator and improvement approaches of making-decision unit.

If $A(u, w, v)^{T}=b$ representing the constraints among weights, the WHDEA model can be expressed as:

$$
\begin{aligned}
& \operatorname{Max} u^{T} y_{j_{0}}+W_{u_{0}}=V_{p} \\
& \text { s.t. } w^{T} x_{j}+v^{T} z_{j}-u^{T} y_{j}-W_{u_{0}} \geq 0, j=1,2, \ldots n \\
& w^{T} x_{j_{0}}+v^{T} z_{j_{0}}=1 \\
& A(u, w, v)^{T}=b, w \geq 0, u \geq 0, v \geq 0
\end{aligned}
$$

\section{Index selection and data sources}

Selecting the value of fixed assets and employees as the inputs, Selecting gross production value as the output.

Data Sources: data collecting from the Fujian Statistical Yearbook.

According to the national classification standard for economic industries (GB/T 4754-2011), Secondary industry includes: mining, manufacturing, power, heat, gas and water production and supply, construction; Tertiary industry includes: wholesale and retail, transportation, warehousing and postal services, accommodation and catering, information transmission, software and information technology services, finance, real estate, leasing and business services, scientific research and technical services Industry, water conservancy, environmental and public facilities management, residents services, repairs and other services, education, health and social work, culture, sports and entertainment, public administration, social security and social organization.

Table 2 Inputs and outputs of various industries in 2014-2016

\begin{tabular}{|l|l|l|l|l|l|l|l|l|l|l|}
\hline & \multicolumn{3}{|l|}{$\begin{array}{l}\text { Fixed asset investment } \\
\text { (Unit: 100 million Yuan) }\end{array}$} & \multicolumn{2}{l|}{$\begin{array}{l}\text { Employees } \\
\text { (Unit: 10000 ) }\end{array}$} \\
\hline \multicolumn{1}{|c|}{ industry } & 2014 & 2015 & 2016 & 2014 & 2015 & 2016 & \multicolumn{2}{l|}{$\begin{array}{l}\text { Gross products } \\
\text { (unit:100 million Yuan) }\end{array}$} \\
\hline $\begin{array}{l}\text { Agriculture, Forestry, } \\
\text { Animal husbandry and } \\
\text { Fishery }\end{array}$ & 442.21 & 617.11 & 818.28 & 2.75 & 2.55 & 2.42 & 2085.04 & 2194.06 & 2444.81 \\
\hline Mining industry & 246.92 & 277.90 & 219.46 & 2.33 & 2.31 & 1.89 & 317.50 & 262.56 & 249.12 \\
\hline Manufacturing & 5105.82 & 6102.88 & 6454.57 & 231.76 & 224.89 & 220.08 & 9523.39 & 9859.8 & 10559.03 \\
\hline $\begin{array}{l}\text { Electricity, Heat, } \\
\text { Gas and Aquatic } \\
\text { production and supply }\end{array}$ & 917.91 & 908.44 & 1143.93 & 8.40 & 8.37 & 8.51 & 585.77 & 697.86 & 641.14 \\
\hline Construction industry & 206.45 & 225.31 & 80.57 & 106.44 & 112.00 & 115.77 & 2112.03 & 2268.86 & 2421.34 \\
\hline $\begin{array}{l}\text { Wholesale and Retail } \\
\text { trade }\end{array}$ & 382.21 & 511.63 & 413.80 & 24.70 & 26.10 & 25.43 & 1961.18 & 2046.29 & 2204.6 \\
\hline
\end{tabular}


Table 2, cont.

\begin{tabular}{|c|c|c|c|c|c|c|c|c|c|}
\hline \multirow[b]{2}{*}{ industry } & \multicolumn{3}{|c|}{$\begin{array}{l}\text { Fixed asset investment } \\
\text { (Unit: } 100 \text { million Yuan) }\end{array}$} & \multicolumn{3}{|c|}{$\begin{array}{l}\text { Employees } \\
\text { (Unit: } 10000 \text { ) }\end{array}$} & \multicolumn{3}{|c|}{$\begin{array}{l}\text { Gross products } \\
\text { (unit:100 million Yuan) }\end{array}$} \\
\hline & 2014 & 2015 & 2016 & 2014 & 2015 & 2016 & 2014 & 2015 & 2016 \\
\hline $\begin{array}{l}\text { Transportation, } \\
\text { Warehousing and } \\
\text { Postal services }\end{array}$ & 1979.45 & 2491.85 & 2678.05 & 18.98 & 20.47 & 19.74 & 1320.35 & 1547.3 & 1685.18 \\
\hline \begin{tabular}{|l|} 
Accommodation and \\
Catering industry \\
\end{tabular} & 226.45 & 263.39 & 191.48 & 9.58 & 9.48 & 9.47 & 374.61 & 398.35 & 421.51 \\
\hline $\begin{array}{l}\text { Information } \\
\text { transmission, Software } \\
\text { and Information } \\
\text { technology services } \\
\end{array}$ & 207.93 & 319.05 & 311.14 & 5.55 & 7.76 & 8.32 & 438.11 & 555.03 & 688.81 \\
\hline Financial industry & 46.59 & 57.10 & 50.57 & 11.87 & 12.34 & 12.68 & 1449.82 & 1681.33 & 1866.17 \\
\hline Real estate industry & 5358.41 & 5366.17 & 5462.43 & 13.33 & 14.28 & 14.45 & 1090.22 & 1077.88 & 1269.67 \\
\hline $\begin{array}{l}\text { Leasing and Business } \\
\text { services }\end{array}$ & 232.24 & 268.96 & 335.97 & 9.74 & 11.07 & 11.09 & 613.21 & 800.04 & 1078.53 \\
\hline \begin{tabular}{|l|} 
Scientific research and \\
Technology services
\end{tabular} & 52.69 & 82.97 & 115.96 & 7.78 & 7.77 & 7.94 & 165.50 & 235.97 & 261.58 \\
\hline $\begin{array}{l}\text { Water, Environment } \\
\text { and Public facilities } \\
\text { management }\end{array}$ & 1787.28 & 2669.14 & 3588.53 & 4.58 & 4.33 & 4.42 & 81.86 & 84.36 & 90.62 \\
\hline $\begin{array}{l}\text { Resident services, } \\
\text { Repairs and Other } \\
\text { services }\end{array}$ & 53.07 & 69.55 & 50.39 & 1.37 & 1.59 & 2.48 & 404.70 & 492.4 & 615.48 \\
\hline Education & 214.45 & 273.38 & 328.17 & 46.44 & 46.26 & 47.53 & 389.38 & 540.36 & 616.68 \\
\hline Health and Social work & 118.63 & 171.94 & 198.67 & 18.74 & 19.24 & 20.27 & 260.34 & 374.86 & 444.63 \\
\hline \begin{tabular}{|l} 
Culture, Sports and \\
Entertainment
\end{tabular} & 257.45 & 265.71 & 323.98 & 3.46 & 3.66 & 3.59 & 308.90 & 331.52 & 367.6 \\
\hline $\begin{array}{l}\text { Public management, } \\
\text { Social security and } \\
\text { Social organizations }\end{array}$ & 305.21 & 358.43 & 341.54 & 32.15 & 33.03 & 33.49 & 573.80 & 530.99 & 592.65 \\
\hline
\end{tabular}

\section{Operating Results}

According to the statistical data in investment of fixed assets, employees, total products, the input-oriented CCR model in DEA is used to calculate the comprehensive technical efficiency of various industries. The calculation operated by DEAP 2.1, Results shown in table 3.

Table3 Comprehensive technical efficiency values of various industries in 2014-2016

\begin{tabular}{|l|l|l|l|l|l|}
\hline Industry & 2016 & 2015 & 2014 & Average & Ranking \\
\hline Resident services, Repairs and Other services & 1 & 1 & 0.996 & 0.999 & 1 \\
\hline Financial industry & 1 & 0.902 & 0.843 & 0.915 & 2 \\
\hline Construction industry & 0.814 & 0.273 & 0.277 & 0.455 & 3 \\
\hline Mining industry & 0.426 & 0.367 & 0.44 & 0.411 & 4 \\
\hline Wholesale and Retail trade & 0.388 & 0.322 & 0.364 & 0.358 & 5 \\
\hline Culture, Sports and Entertainment & 0.331 & 0.292 & 0.288 & 0.304 & 6 \\
\hline Leasing and Business services & 0.354 & 0.279 & 0.245 & 0.293 & 7 \\
\hline Real estate industry & 0.284 & 0.244 & 0.264 & 0.264 & 8 \\
\hline $\begin{array}{l}\text { Information transmission, Software and Information } \\
\text { technology services }\end{array}$ & 0.283 & 0.236 & 0.269 & 0.263 & 9 \\
\hline Transportation, Warehousing and Postal services & 0.276 & 0.244 & 0.225 & 0.248 & 10 \\
\hline Electricity, Heat, Gas and Water production and supply & 0.243 & 0.269 & 0.225 & 0.246 & 11 \\
\hline Manufacturing & 0.176 & 0.165 & 0.163 & 0.168 & 12 \\
\hline Accommodation and Catering industry & 0.18 & 0.157 & 0.152 & 0.163 & 13 \\
\hline Scientific research and Technology services & 0.155 & 0.161 & 0.129 & 0.148 & 14 \\
\hline Health and Social work & 0.12 & 0.11 & 0.086 & 0.105 & 15 \\
\hline Public management, Social security Social organizations & 0.095 & 0.085 & 0.098 & 0.093 & 16 \\
\hline Education & 0.079 & 0.073 & 0.056 & 0.069 & 17 \\
\hline Water, Environment and Public facilities management & 0.066 & 0.063 & 0.058 & 0.062 & 18 \\
\hline average & 0.348 & 0.291 & 0.288 & & \\
\hline
\end{tabular}




\section{Conclusions and Suggestions}

From table 3, the overall technical efficiency of the second and third industry in Fujian is relatively low. The averages of 2016, 2015, and 2014 are 0.348, 0.291, and 0.288 respectively. Under the same circumstances, there were $65.2 \%, 70.9 \%$, and $71.2 \%$ waste in the three years' investment. Because of the relative efficiency of DEA measures, in eighteen industries, the relatively more efficient ones are the resident services, repairs and other service industries in the tertiary industry and the financial industry. The average annual comprehensive technical efficiency was 0.999, 0.915, which was far higher than that of other industries. In 2016, resident services, repair and other service industries as well as the financial industry have achieved DEA efficiency and are at the front of production. The average of comprehensive technical efficiency ranks third and fourth are the construction and mining industries of the second industry, the averages are $0.455,0.411$ respectively, the efficiency is not high, and it is almost the half of the efficiency of the other service industries and the financial industry. The efficiency values are very unsatisfactory in the industries of public management, social security and social organization, education, water conservancy, environment and public facilities management. Their efficiency values are less than 0.1. It means that the resource allocation capacity of these three industries is relatively insufficient.

Table4 Comparison of averages of the second industry and the tertiary industry

\begin{tabular}{|l|l|l|l|l|}
\hline Industry & 2016 & 2015 & 2014 & Average \\
\hline Secondary industry & 0.415 & 0.269 & 0.276 & 0.320 \\
\hline Tertiary Industry & 0.329 & 0.298 & 0.291 & 0.306 \\
\hline
\end{tabular}

From Table 4, we can see that from the horizontal comparison point of view, the average of the three-year comprehensive technical efficiency of the second industry and the third industry is very small, the second industry is 0.320 , the third industry is 0.306 , and the gap is only $1.4 \%$. From a longitudinal comparison, the overall technical efficiency value of the secondary industry and the tertiary industry has risen with the passage of time, but the increase has been modest. In 2014 and 2015, the overall technical efficiency of the secondary industry was lower than that of the tertiary industry. However, in 2016, the combined technical efficiency values of the secondary and tertiary industries were 0.415 and 0.329 , respectively. The efficiency of the secondary industry was higher than that of the tertiary Industry.

According to the analysis of empirical results, the following suggestions are put forward for the economic development:

(1) To change the mode of economic growth and accelerate the adjustment of industrial structure. In order to change the mode of economic growth and maintain high economic efficiency, Fujian must focus on accelerating the adjustment of the industrial structure and to increase the efficiency of resource allocation and output efficiency.

(2) To increase investment in human capital and play the role of technological innovation in promoting economic development. To optimize the structure of human capital, To promote the application of advanced technologies in economic development, and then To increase the level of technical efficiency in economic development, and To promote the sustainable economic development of Fujian .

(3) To promote the coordinated development of the economy. The DEA effective industry will promote DEA-ineffective industries such as public management, social security and social organizations, education, water conservancy, environment, and public facilities management, and to promote the coordinated development of the economy. Using market mechanisms to introduce redundant resources of low-efficiency industries into industries with higher economic returns, to reduce the scale of returns to diminish the investment scale of the industry and to reduce the phenomenon of under-production, to achieve a common increase in the economic efficiency of various industries, and to promote the various industries in the province Balanced development. 


\section{Acknowledgement}

Project supported by the Foundation for Social Sciences research of Fujian Province, No.FJ2016B138.

\section{References}

[1] Zhang Ping, Liu Xia-hui. China's economic growth report (2011-2012) :The structural deceleration in China's economy and regional transformation and upgrading, Social sciences academic press, 2013,pp1

[2] http://www.chinabgao.com/enterprise/11271.html

[3] Lin Kan. No.7 in the nation's digital economy development, Fujian Daily, 2017-11-30

[4] Ma Zhan-xin, Tang Huan-wen. DEA Method for comprehensive evaluation of macroeconomic development, System engineering, 2002 (2): 30-34

[5] Hu Jin-tao. Unswervingly marching along the road of socialism with Chinese characteristics and striving to build a well-off society in an all-round way--Report on the Eighteenth National Congress of the Communist Party of China. http://www.xinhuanet.com. Com/18cpcnc/2012-11/17/c_113711665.htm. 